\title{
Primer Dismenorede Tedavi Yaklaşımları
}

\section{Treatment Modalities in Primary Dysmenorrhea}

\section{Özet}

Kadınlarda dismenore sık karşılaşılan, hastanın yaşam kalitesini azaltan, önemli bir sağlık sorunudur. Dismenorenin sağlık sistemi üzerine ekonomik yükü de oldukça fazladır. Dismenore, şiddetine bağlı olarak iş, okul ve diğer günlük aktivitelerden alıkoyabilmektedir. Primer dismenore, herhangi bir pelvik patoloji olmadan, menstrüasyon sırasında alt abdominal bölgede görülen, tekrarlayan, kramp tarzında ağrıdır. Sekonder dismenore ise pelvik patoloji varlığında görülen menstrüasyon ağrısıdır. Primer dismenore reprodüktif yaş grubunda, özellikle de adölesanlarda çok sık rastlanan bir problem iken, sekonder dismenore kırklı ve ellili yaşlarda daha sık görülür. Doğru tanı için, semptomların detaylı olarak değerlendirilmesi ve kapsamlı bir fizik muayene çok önemlidir. Hastalığın tedavi seçenekleri için konservatif yaklaşımlardan medikal tedaviye kadar, geniş bir yelpaze söz konusudur. Bu derlemede primer dismenoreyi güncel bilgiler eşliğinde ele almak ve tedavi yaklaşımları konusunda bilgi vermek amaçlanmıştır.

Anahtar Sözcükler: primer dismenore; adölesan; tedavi; kadın

\section{Abstract}

Dysmenorrhea is an important health care problem. It is common in women and reduces the quality of life. Economic burden of dysmenorrhea on the health system is quite high. Depending on the severity of symptoms, it may restrict work performance and school and other daily activities. Primary dysmenorrhea refers to the presence of recurrent, crampy, lower abdominal pain occurring during menses in the absence of any demonstrable pathology. Secondary dysmenorrhea refers to painful menstruation in the presence of a pelvic pathology. Primary dysmenorrhea is a common problem experienced by women in their reproductive years. Secondary dysmenorrhea is more common among the women in the fourth and fifth decades of life. For correct diagnosis, a detailed evaluation of the symptoms and a comprehensive physical examination is very important. Treatment options vary from conservative approaches to medical treatments. In this review, we intended to provide contemporary information on the definition and evaluation of primary dysmenorrhea, and treatment options.
\end{abstract}

Keywords: primary dysmenorrhea; adolescents; treatment; woman
Ayşe Topcu Akduman', Oya Çimen Budur ${ }^{2}$

1 Düzce Atatürk Devlet Hastanesi, Kadın Hastalıkları ve Doğum Kliniği, Düzce, Türkiye

2 Istanbul Bahçelievler Devlet Hastanesi, Anesteziyoloji ve Reanimasyon Kliniği, İstanbul, Türkiye

Geliş Tarihi /Received : 25.04.2016 Kabul Tarihi /Accepted: 26.05.2016

Sorumlu Yazar/Corresponding Author Op. Dr. Ayşe Topcu Akduman Düzce Atatürk Devlet Hastanesi, Kadın Hastalıkları ve Doğum Kliniği, Merkez, Düzce

E-mail:drayse58@gmail.com 


\section{GíRiş}

Dismenore olarak da bilinen ağrılı menstrüasyon, sağlık, sosyal ve ekonomik etkileri olan, sık görülen jinekolojik hastalıklardan biridir. Pelvik patoloji saptanmayan hastalarda, mensle birlikte ya da menstrüasyondan hemen önce başlayan, 12-72 saat devam eden, tekrarlayan kramp tarzı suprapubik pelvik ağrı olarak tanımlanmaktadır (1). Menarştan 1 ila 2 yıl sonra başlar, daha çok genç kadınlarda görülmesine rağmen 40’lı yaşlara kadar devam edebilir (2). Bulantı, kusma, ishal, baş ağrısı, baş dönmesi ve karın ağrısı eşlik edebilir. Yapılan çalışmalarda dismenorenin prevalansının, dünya genelinde $\% 50$ ila $\% 90$ arasında olduğu görülmektedir $(3,4)$. Adölesanlarda ise bu oran biraz daha fazladır ve \%60 ila \%93 arasında değişmektedir $(3,5)$. Fakat tıbbi destek için sağlık kurumuna başvurma oranı \%15'te kalmaktadır (6). Dismenore pek çok hastanın günlük aktivitelerini kısıtlamaktadır. Kanada’da 18 yaşından büyük 934 primer dismenoreli kadın ile yapılan bir çalışmada $\% 60$ oranında orta ya da ciddi şiddette ağrı tanımlanmıştır. Bu hastaların \%50’sinde ağrının günlük aktiviteyi kısıtlayıcı seviyede olduğu ve hastaların \%17'sinin dismenore sebebiyle okul ya da işyerine gidemediği bildirilmiştir (7).

\section{ETIYOLOJi}

Primer dismenorenin nedeni tam olarak anlaşılamasa da, endometriyum kökenli prostoglandinlerin, primer dismenore ile ilişkili olduğu düşünülmektedir. Primer dismenoreli hastalarda özellikle endometriyumda PGF2alfa ve PGF2alfa/PGE2 oranının arttığ1 gösterilmiştir $(8,9)$. Prostoglandinlerin miyometriyum kontraksiyonlarını uyararak, uterus kan akımını ve oksijenlenmesini azaltarak ağrıya neden oldukları düşünülmektedir. Menstrüasyon sırasinda, uterusun bazal kontraksiyon seviyesi olan 10 mmHg'dan 150180 mmHg'nın üzerine çıkmasıyla, uterin iskemi gelişmekte ve açığa çıkan anaerobik metabolitler Tip $C$ ağrı liflerini uyararak dismenoreye neden olmaktadır (10). Prostoglandinlerin sistemik dolaşıma geçmesi ve gastrointestinal sistemi uyarmasiyla bulantı, kusma ve ishal gibi semptomlar görülebilmektedir. Ayrıca, prostoglandin sentez inhibitörlerinin kullanımıyla dismenorenin azalması, prostoglandinlerin etiyolojideki rolünü desteklemektedir $(11,12)$.
Prostoglandin üretimi progesteron tarafından kontrol edilir. Menstrüasyondan hemen önce progesteron seviyesinin düşmesiyle, prostoglandin seviyesi artar, bu da dismenorenin sadece ovulatör sikluslarda görülmesini açıklar (10).

Şiddetli dismenoresi ve normal laparoskopik bulguları olan bazı hastalarda ise, prostoglandin artışı saptanmamıştır. Bu vakaların prevalansı bilinmemektedir. Antidiüretik hormonun etkili olabileceği öne sürülmekle birlikte rolü tartışmalıdır (13).

\section{PRIMER DISMENOREDE TEDAVI}

Bu makalede yaşam kalitesini düşüren primer dismenore tedavisi konusunda rasyonel bir yaklaşımın sunulması amaçlanmaktadır. Primer dismenore tedavisi konservatif yaklaşımlardan medikal tedaviye kadar geniş bir yelpazede yer alır.

Tedavi protokolü, ağriya sebep olabilecek jinekolojik hastalıklar dışlandıktan sonra, bireysel ihtiyaçlara göre belirlenir. Menstrüel ağrının şiddeti ve günlük faaliyetleri kısitlaması, tedavi kararının verilmesi ve yaklaşımın belirlenmesinde yardımcı olmaktadır.

\section{A-MEDIKAL TEDAVI}

Medikal tedavinin temelini, nonsteroid antiinflamatuvar ilaçlar (NSAİì) ve hormonal kontraseptifler oluşturur.

\section{NSAii'ler}

NSAIII'lerin endometriyal prostoglandin üretimini azaltarak, primer dismenorede ağrıyı azalttığı düşünülmektedir. Aynı zamanda direkt santral sinir sistemini etkileyerek de ağrıyı azaltabilir (13).

NSAIII'ler, siklooksijenaz (COX) enzimini inhibe ederek, prostaglandin oluşumunu engellerler. COX enzimi, COX-1 ve COX-2 olmak üzere iki şekilde bulunmaktadır. Geleneksel NSAIII’ler COX-1 ve COX-2 enzimlerini inhibe eder. Daha seçici NSAIII'ler ise tek başına COX-2 enzimini inhibe etmektedir.

NSAIII'lerin hafif nörolojik (baş ağrısı, uyku hali, baş dönmesi) ve gastrointestinal sistem (hazımsızlık, bulantı) ile ilgili yan etkileri görülebilmektedir. Ancak dismenorenin daha sık görüldüğü genç hastalarda daha iyi tolere edilmektedir. 
Yapılan birçok randomize çalışma NSAIII’lerin primer dismenorenin tedavisinde etkili olduğunu göstermiştir. Yetmiş üç randomize çalışmanın değerlendirildiği bir Cochrane sistematik derlemesinde NSAIII'lerin plasebodan ve parasetamolden daha etkili olduğu gösterilmiştir (13).

Hangi NSAIİ'nin daha etkili olduğunu ise net olarak söylemek mümkün değildir $(13,14)$. Etkinlik açısından aralarında fark olmadığını gösteren çalışmalar olsa da (15-17), bazı çalışmalarda fenamatların (mefenamik asit, tolfenamik asit, flufenamik asit, meklofenamat, bromfenak) fenilpropiyonik asit türevlerine (ibuprofen, naproksen) oranla daha etkili oldukları bildirilmiştir $(18,19)$.

Bazı COX-2 inhibitörleri (selekoksib, ABD’de kardiyovasküler risk uyarısı ile siyah pakette satılmaktadır), şiddetli primer dismenore tedavisi için onaylanmıştır. Cochrane sistematik derlemesinde, nonselektif NSAIİ'ler ile COX-2 inhibitörlerinin (selekoksib ve etorikoksib) karşılaştırılmasında, selekoksibin naproksenden daha az etkili olduğu, etorikoksibin ise naproksen ile aynı etkinliğe sahip olduğu gösterilmiş ve iki grup arasında tolere edilebilirlik açısından fark saptanmamıştır (14). Bu ilaçlar NSAIII'lerden daha pahalıdır. Fakat NSAIII ile ilgili gastroduodenal toksisite açısından yüksek risk altında olan hastalarda yararlı olabilir. Ancak bu ilaçların çoğuyla ilgili ciddi yan etkilerin olması nedeniyle kullanılması önerilmemektedir.

Prostoglandinler ovulasyonda önemli rol oynamaktadır, özellikle COX-2 inhibitörleri, ovulasyonu geciktirebilir ya da önleyebilir. Gebelik planlayan hastalarda NSAİI’ler regl döneminde güvenle kullanılabilir. Fakat hastanın infertilite problemi varsa genel yaklaşım olarak, bu ilaçların dozu azaltılması ya da kullanılmamaları önerilmektedir (20).

Hangi NSAIİ ile tedaviye başlanacağıyla ilgili net bir kural olmasa da genel yaklaşım, fenilpropiyonik asit ile tedaviye başlamaktır. İbuprofen $2.400 \mathrm{mg}$ olarak regl belirtileriyle birlikte, 6-8 saat aralıklarla başlanır, semptomlara göre 3-4 gün devam edilir. $\mathrm{Bu}$ yaklaşımın avantajı ibuprofenin kanıtlanmış etkinliği, reçeteye gerek olmaması ve ucuz olmasıdır.

Fenilpropiyonik asit türevleri ile ağrida yeteri derecede rahatlama olmuyorsa fenamatlar kullanılabilir (ör: mefenamik asit $500 \mathrm{mg}$ ile başlanıp, her altı saatte bir $250 \mathrm{mg}$ olacak şekilde üç gün süre ile devam edilebilir). Primer dismenorede sıklıkla kullanılan NSAIİ'lerin önerilen dozları Tablo 1'de özetlenmiştir $(13,21)$.

\section{2. Östrojen-Progestin İçeren Hormonal Kontraseptifler}

Kontrasepsiyon ihtiyacı olan dismenoreli kadınların ilk basamak tedavisinde, östrojen-progesteron içeren hormonal kontraseptifler önerilebilir. İçerdikleri sentetik östrojen ve progesteronla ovulasyonu baskılar ve endometriyumun zaman içerisinde incelmesine neden olurlar. Böylece endometriyum da prostoglandin prekürsörü olan araşidonik asit nispeten daha az salgılanır. Endometriyumdaki bu değişikliklerin sonucu olarak, kanama miktarı ve rahim kasılmaları azalır $(22,23)$.

Oral kontraseptifler içerdikleri östrojen miktarına ve progesteron çeşidine göre farklılıklar gösterir. Östrojen ve progesterona bağlı olarak yan etkiler görülebilir. Östrojene bağlı bulantı, baş ağrısı, memelerde şişkinlik; progesterona bağlı akne, kilo artışı, depresyon görülebilir. Bununla birlikte plasebo kontrollü çift kör çalışmalarda bu yan etkilerin çoğunun benzer olduğu gösterilmiştir (23). Venöz tromboemboli gibi daha ciddi yan etkiler ise çok daha az görülmektedir.

Cochrane sistematik derlemesinde, östrojen-progesteron içeren hormonal kontraseptiflerin dismenorede etkili olduğu gösterilmiştir. Birkaç çalışmada düşük ( $\leq 35 \mu \mathrm{g})$ ve orta doz (>35 $\mu \mathrm{g})$ östrojen içeren preparatlar arasında etkinlik açısından fark olmadığı ve bir çalışmada 3. kuşak progesteron içeren preparatların 1. ve 2. kuşağa göre daha etkili olduğu bildirilmiştir (23).

\section{Sadece Progesteron İçeren İlaçlar}

Progesteron, özellikle endometriyal atrofiyi uyararak etki gösterir. Fakat ovulasyonu inhibe etmez. Dismenorede sadece progesteron kullanımı ile ilgili yeterli veri yoktur. Hormonal kontraseptif kullanımının kontrendike olduğu hastalarda tedavi alternatifi olabilir. Ancak ara kanamalar sadece progesteron içeren ilaçların kullanılmasında daha sık görülür.

\section{Rahim İçi Levonorgestrel (LNg20; Mirena $\left.{ }^{\circledR}\right)$}

Randomize çalışmaların değerlendirildiği bir derlemede, (LNg20; Mirena) ile dismenorede azalma bildirilmiştir $(25,26)$. Gebe kalmak istemeyen hastalarda, tek bir müdahale ile 5 yıllık tedavi seçeneği sunmaktadır (25). 
Tablo 1. Primer dismenorede önerilen nonsteroid antiinflamatuvar ilaçların dozları $(13,20)$

\begin{tabular}{|c|c|c|c|}
\hline İlaç & Başlangıç dozu & İdame dozu, gerektiğinde & $\begin{array}{c}\text { Kısa süreli kullanımda( } \leq 3 \text { gün }) \\
\text { maksimum günlük doz }\end{array}$ \\
\hline \multicolumn{4}{|c|}{ Propiyonik asit türevleri } \\
\hline İbuprofen & $400-600 \mathrm{mg}$ & $400-600 \mathrm{mg}, 4-6$ saate bir & $2.400 \mathrm{mg}$ \\
\hline Naproksen sodyum & $550 \mathrm{mg}$ & $275 \mathrm{mg}, 6-8$ saatte bir & $1.375 \mathrm{mg}$ \\
\hline Fenoprofen & $200 \mathrm{mg}$ & $200 \mathrm{mg}, 4-6$ saate bir & $3.200 \mathrm{mg}$ \\
\hline Ketoprofen & $50 \mathrm{mg}$ & $25-50 \mathrm{mg}, 6-8$ saate bir & $300 \mathrm{mg}$ \\
\hline \multicolumn{4}{|l|}{ Fenamat türevleri } \\
\hline Mefenamik asit & $500 \mathrm{mg}$ & $250 \mathrm{mg}, 6$ saate bir & $1.000 \mathrm{mg}$ \\
\hline Meklofenamat & $100 \mathrm{mg}$ & $50 \mathrm{mg}, 4-6$ saate bir & $400 \mathrm{mg}$ \\
\hline \multicolumn{4}{|l|}{ Asetik asit türevleri } \\
\hline İndometazin & $25 \mathrm{mg}$ & $25 \mathrm{mg}$, günde $3 \mathrm{kez}$ & $150 \mathrm{mg}$ \\
\hline Tolmetin & $400 \mathrm{mg}$ & $400 \mathrm{mg}$, günde $3 \mathrm{kez}$ & $1.800 \mathrm{mg}$ \\
\hline Diklofenak & $75-100 \mathrm{mg}$ & $50 \mathrm{mg}$, günde $3 \mathrm{kez}$ & $150 \mathrm{mg}$ (100 mg, 2. gün başlanabilir) \\
\hline Etodolak & $400 \mathrm{mg}$ & 200-400 mg, 6-8 saate bir (hızlı salınım) & $1.000 \mathrm{mg}$ (hızlı salınım) \\
\hline \multicolumn{4}{|l|}{ Salisilatlar (nonasetile) } \\
\hline Diflunisal & $1000 \mathrm{mg}$ & $500 \mathrm{mg}$, günde $2 \mathrm{kez}$ & $1.500 \mathrm{mg}$ \\
\hline \multicolumn{4}{|l|}{ Oksikamlar } \\
\hline Meloksikam & $7,5 \mathrm{mg}$ & $7,5 \mathrm{mg}$, günde tek doz & $15 \mathrm{mg}$ \\
\hline Piroksikam & $20 \mathrm{mg}$ & 10-20 mg, günde tek doz & $20 \mathrm{mg}$ \\
\hline
\end{tabular}

\section{Tokolitikler}

Tokolitikler, primer dismenorede görülen uterin kontraksiyonları azaltmak için kullanılabilir. Primer dismenorenin etiyolojisinde, uterin kontraksiyonların da rolü vardır. Nitrik oksit, nitrogliserin ve kalsiyum kanal blokerleri tokolitik etkileri nedeniyle, primer dismenore tedavisi açısından araştırılmaktadır.

Gliseril trinitrat. Gliseril trinitratın, dismenorenin tedavisinde etkili olduğu randomize çalışmalarla gösterilmiştir. Ancak, NSAIII (günlük $50 \mathrm{mg}$ diklofenak) ile gliseril trinitratın karşılaştırıldığı çalışmalarda, gliseril trinitratın, NSAIII'den daha az etkili olduğu ve yan etkilerinin daha fazla olduğu gösterilmiştir. Düşük tolere edilebilirliği ve baş ağrısı yan etkisi ise kullanımını sınırlamaktadır (27).

Nifedipin. Nifedipinin, uterus kasılmalarını azaltarak, primer dismenoreli kadınlarda ağrıyı azalttığ 1 yapılan çalışmalarda gösterilmiştir. Fakat yüzde kızarıklık, taşikardi, baş ağrısı gibi yan etkilerin yüksek oranda görülmesi ve kardiyovasküler etkilerinin olması kullanımını sınırlamaktadır (28-31).

Magnezyum. Yapılan küçük çaplı randomize çalışmalarda, magnezyumun dismenoreyi hafifletmek için plasebodan daha etkili olduğu ve iyi tolere edildiği gösterilmiştir. Ancak, yüksek ilaç kullanımına uyumsuzluk oranları, optimum doz belirsizliği gibi durumlar nedeniyle dismenore tedavisindeki yerinin belirlenmesi güçtür $(32,33)$.

\section{B-ALTERNATIF TEDAVILER}

\section{Akupunktur}

Akupunktur ile ilgili yapılan çalışmaların tümünde dismenore de etkili olduğu gösterilmiştir. Ancak tedavideki yerinin tam olarak belirlenebilmesi için, yeterli örneklem büyüklüğ̈̈ olan, randomize, kör, plasebo kontrollü çalışmalara ihtiyaç duyulmaktadır (34). Bununla birlikte akupunktur, medikal tedavi almak istemeyen hastalar için alternatif olarak değerlendirilebilir.

\section{Transkütanöz Elektriksel Sinir Stimulasyo- nu (TENS)}

Altı aylık medikal tedaviye rağmen dismenore semptomlarında gerileme olmaması durumunda, hasta tedaviye dirençli olarak kabul edilir. TENS bu hastalar için uygun bir seçenek olabilir.

TENS, deri yüzeyine yakın sinirlerin, cilde yapıştırılan elektrotlar yardımıyla değişik frekans ve yoğunlukta elektriksel sinyallerle uyarılmasını ifade etmektedir. TENS'in iki yolla etkili olduğu kabul edilmektedir. Primer dismenorede TENS ile ağrı kontrolü, uterus hipoksi ve kontraktilitesinin neden olduğu ağrı sinyallerinin eşiğini yükseltilmesi ve endorfin salını- 
mını uyarılması ile gerçekleştiği düşünülmektedir.

Yapılan çalışmalarda yüksek frekanslı TENS'in, plasebodan daha etkili olduğu gösterilmiştir (35). Medikal tedaviyle TENS'in karşılaştırıldığı çalışmalarda, ibuprofenin TENS'ten daha etkili olduğu ancak naproksenle yüksek frekanslı TENS arasında ağrıyı azaltmada fark olmadığı bildirilmiştir $(36,37)$.

$\mathrm{Bu}$ yöntem, ilaç kullanmak istemeyen hastalar için iyi bir alternatif gibi görünmesine rağmen tek başına TENS ile elde edilen ağrı kontrolü ilaçlardan daha azdır.

\section{Isı Uygulaması}

Yapılan çalışmalarda ısı uygulamasının dismenorede ağrıyı anlamlı derecede azalttığı bildirilmiştir. Pek çok kadın, medikal tedaviyi daha kolay uygulanabilir bulsa bile, ssı uygulamasının herhangi bir yan etkisi yoktur ve diğer tedavilerin etkinliklerini artırmaktadır. Seksen dört dismenoreli hasta ile yapılan randomize kontrollü bir çalışmada, ısı uygulanmasının en az ibuprofen kadar etkili olduğu gösterilmiştir (38). Isı uygulaması ile asetaminofenin karşılaştırıldığı, 367 hasta ile yapılan başka bir randomize kontrollü çalışmada, ısı uygulamasının asetaminofenden daha etkili olduğu ve daha iyi tolere edildiği ortaya konmuștur (39).

\section{Diyet ve Vitamin}

Diyet değişiklikleri ve vitamin tedavisinin dismenorenin şiddetini azalttığı rapor edilmişse de, literatürdeki veriler birkaç küçük çaplı randomize kontrollü çalışma ile sınırlıdır (27). Yapılan iki randomize çalışmada, E vitamininin dismenorede ağrı ve kanama miktarını azalttığı gösterilmiştir $(40,41)$. Cochrane sistematik derlemesinde B1 ve B6 vitaminlerinin ve balık yağının (omega-3 yağ asitleri) plasebodan daha etkili olduğu bildirilmiștir (42).

\section{SONUÇ}

Primer dismenoreli hastalara yaklaşımda temel amaç, hastaların ağrılarında yeterli rahatlamanın temin edilmesidir. İlk yaklaşım, sıcak uygulama ya da egzersiz gibi farmakolojik olmayan yöntemlerin denenmesini içerir. Hastanın semptomlarında düzelme olmaması durumunda uygulanacak farmakolojik yaklaşım ise hastanın bireysel ihtiyaçlarına göre belirlenir. Doğum kontrolü isteyen hastalar için hormonal tedavi daha faydalı iken, hormonal tedavi kullanmayı tercih etmeyen hastalarda NSAIII'ler daha doğru bir seçim- dir. Ancak, bazı durumlarda her iki tedavi seçeneğine birden başvurmak gerekebilir. NSAIII'ler ve hormonal kontraseptif yöntemlerle rahatlama sağlanmayan hastalar için standart bir yaklaşım yoktur. Üç ay tedaviye rağmen fayda görmeyen hastalarda endometriyozis düşünülerek ampirik olarak GnRH agonistleri önerilebilir. Ayrıca, transkütanöz elektriksel sinir stimülasyonu ya da diğer alternatif tedaviler, birer seçenek olarak tedavi yaklaşımına eklenebilir.

\section{KAYNAKLAR}

1. Berkley KJ. Primary dysmenorrhea: an urgent mandate. Pain Clin Updates. 2013;21(3):1-8.

2. Jones AE. Managing the pain of primary and secondary dysmenorrhoea. Nurs Times. 2004;100(10):40-3.

3. Campbell MA, McGrath PJ. Use of medication by adolescents for the management of menstrual discomfort. Arch Pediatr Adolesc Med. 1997;151(9):905-13.

4. Hillen TI, Grbavac SL, Johnston PJ, Straton JA, Keogh JM. Primary dysmenorrhea in young Western Australian women: prevalence, impact, and knowledge of treatment. J Adolesc Health. 1999;25(1):40-5.

5. Johnson J. Level of knowledge among adolescent girls regarding effective treatment for dysmenorrhea. J Adolesc Health Care. 1988;9(5):398-402.

6. Klein JR, Litt IF. Epidemiology of adolescent dysmenorrhea. Pediatrics. 1981;68(5):661-4.

7. Burnett MA, Antao V, Black A, Feldman K, Grenville A, Lea $\mathrm{R}$ ve ark. Prevalence of primary dysmenorrhea in Canada. J Obstet Gynaecol Can. 2005;27(8):765-70.

8. Willman EA, Collins WP, Clayton SG. Studies in the involvement of prostaglandins in uterine symptomatology and pathology. Br J Obstet Gynaecol. 1976;83(5):337-41.

9. Bieglmayer C, Hofer G, Kainz C, Reinthaller A, Kopp B, Janisch $\mathrm{H}$. Concentrations of various arachidonic acid metabolites in menstrual fluid are associated with menstrual pain and are influenced by hormonal contraceptives. Gynecol Endocrinol. 1995;9(4):307-12.

10. Dawood MY. Primary dysmenorrhea: advances in pathogenesis and management. Obstet Gynecol. 2006;108(2):428-41.

11. Gynec Chan WY, Dawood MY, Fuchs F. Relief of dysmenorrhea with the prostaglandin synthetase inhibitor ibuprofen: effect on prostaglandin levels in menstrual fluid. Am J Obstet Gynecol. 1979;135(1):102-8.

12. Altunyurt S, Göl M, Altunyurt S, Sezer O, Demir N. Primary dysmenorrhea and uterine blood flow: a color Doppler study. J Reprod Med. 2005;50(4):251-5.

13. Marjoribanks J, Proctor M, Farquhar C, Derks RS. Nonsteroidal anti-inflammatory drugs for dysmenorrhoea. Cochrane Database Syst Rev. 2010;(1):CD001751. 
14. Marjoribanks J, Ayeleke RO, Farquhar C, Proctor M. Nonsteroidal anti-inflammatory drugs for dysmenorrhoea. Cochrane Database Syst Rev. 2015;(7):CD001751.

15. Owen PR. Prostaglandin synthetase inhibitors in the treatment of primary dysmenorrhea. Outcome trials reviewed. Am J Obstet Gynecol. 1984;148(1):96-103.

16. Zhang WY, Li Wan Po A. Efficacy of minor analgesics in primary dysmenorrhoea: a systematic review. Br J Obstet Gynaecol. 1998;105(7):780-9.

17. Zahradnik HP, Hanjalic-Beck A, Groth K. Nonsteroidal anti-inflammatory drugs and hormonal contraceptives for pain relief from dysmenorrhea: a review. Contraception. 2010;81(3):185-96.

18. Budoff PW. Use of mefenamic acid in the treatment of primary dysmenorrhea. JAMA. 1979;241(25):2713-6.

19. Milsom I, Minic M, Dawood MY, Akin MD, Spann J, Niland NF ve ark. Comparison of the efficacy and safety of nonprescription doses of naproxen and naproxen sodium with ibuprofen, acetaminophen, and placebo in the treatment of primary dysmenorrhea: a pooled analysis of five studies. Clin Ther. 2002;24(9):1384-400.

20. Norman RJ, Wu R. The potential danger of COX-2 inhibitors. Fertil Steril. 2004;81(3):493-4.

21. Smith RP, Kaunitz AM. Treatment of primary dysmenorrhea in adult women. UpToDate, Inc [Internet]. [Son güncelleme tarihi: Nisan 2016; son erişim tarihi: $26 \mathrm{Ma}-$ y1s 2016]. Erişim: http://www.uptodate.com/contents/ treatment-of-primary-dysmenorrhea-in-adult-women

22. Harada T, Momoeda M, Terakawa N, Taketani Y, Hoshiai $\mathrm{H}$. Evaluation of a low-dose oral contraceptive pill for primary dysmenorrhea: a placebo-controlled, double-blind, randomized trial. Fertil Steril. 2011;95(6):1928-31.

23. Wong CL, Farquhar C, Roberts H, Proctor M. Oral contraceptive pill for primary dysmenorrhoea. Cochrane Database Syst Rev. 2009;(4):CD002120.

24. Goldzieher JW, Zamah NM. Oral contraceptive side effects: where's the beef? Contraception. 1995;52(6):327-35.

25. Bahamondes L, Petta CA, Fernandes A, Monteiro I. Use of the levonorgestrel-releasing intrauterine system in women with endometriosis, chronic pelvic pain and dysmenorrhea. Contraception. 2007;75(6 Suppl):S134-9.

26. Lindh I, Milsom I. The influence of intrauterine contraception on the prevalence and severity of dysmenorrhea: a longitudinal population study. Hum Reprod. 2013;28(7):1953-60.

27. Facchinetti F, Sgarbi L, Piccinini F, Volpe A. A comparison of glyceryl trinitrate with diclofenac for the treatment of primary dysmenorrhea: an open, randomized, cross-over trial. Gynecol Endocrinol. 2002;16(1):39-43.

28. Sandahl B, Ulmsten U, Andersson KE. Trial of the calcium antagonist nifedipine in the treatment of primary dysmenorrhoea. Arch Gynecol. 1979;227(2):147-51.

29. Ulmsten U. Calcium blockade as a rapid pharmacological test to evaluate primary dysmenorrhea. Gynecol
Obstet Invest. 1985;20(2):78-83.

30. Andersson KE, Ulmsten U. Effects of nifedipine on myometrial activity and lower abdominal pain in women with primary dysmenorrhoea. Br J Obstet Gynaecol. 1978;85(2):142-8.

31. Gaviño Ambriz S, Gaviño Gabiño F, Ahued Ahued JR. Use of a calcium antagonist in the management of primary dysmenorrhea. Ginecol Obstet Mex. 1986;54:208-10.

32. Fontana-Klaiber H, Hogg B. Therapeutic effects of magnesium in dysmenorrhea. Schweiz Rundsch Med Prax. 1990;79(16):491-4.

33. Seifert B, Wagler P, Dartsch S, Schmidt U, Nieder J. Magnesium--a new therapeutic alternative in primary dysmenorrhea. Zentralbl Gynakol. 1989;111(11):755-60.

34. Abaraogu UO, Tabansi-Ochuogu CS. As acupressure decreases pain, acupuncture may improve some aspects of quality of life for women with primary dysmenorrhea: a systematic review with meta-analysis. J Acupunct Meridian Stud. 2015;8(5):220-8.

35. Proctor ML, Smith CA, Farquhar CM, Stones RW. Transcutaneous electrical nerve stimulation and acupuncture for primary dysmenorrhoea. Cochrane Database Syst Rev. 2002;(1):CD002123.

36. Dawood MY, Ramos J. Transcutaneous electrical nerve stimulation (TENS) for the treatment of primary dysmenorrhea: a randomized crossover comparison with placebo TENS and ibuprofen. Obstet Gynecol. 1990;75(4):656-60.

37. Milsom I, Hedner N, Mannheimer C. A comparative study of the effect of high-intensity transcutaneous nerve stimulation and oral naproxen on intrauterine pressure and menstrual pain in patients with primary dysmenorrhea. Am J Obstet Gynecol. 1994;170(1):123-9.

38. Akin MD, Weingand KW, Hengehold DA, Goodale MB, Hinkle RT, Smith RP. Continuous low-level topical heat in the treatment of dysmenorrhea. Obstet Gynecol. 2001;97(3):343-9.

39. Akin M, Price W, Rodriguez G Jr, Erasala G, Hurley G, Smith RP. Continuous, low-level, topical heat wrap therapy as compared to acetaminophen for primary dysmenorrhea. J Reprod Med. 2004;49(9):739-45

40. Ziaei S, Zakeri M, Kazemnejad A. A randomised controlled trial of vitamin $\mathrm{E}$ in the treatment of primary dysmenorrhoea. BJOG. 2005;112(4):466-9.

41. Ziaei S, Faghihzadeh S, Sohrabvand F, Lamyian M, Emamgholy T. A randomised placebo-controlled trial to determine the effect of vitamin $\mathrm{E}$ in treatment of primary dysmenorrhoea. BJOG. 2001;108(11):1181-3.

42. Proctor ML, Murphy PA. Herbal and dietary therapies for primary and secondary dysmenorrhoea. Cochrane Database Syst Rev. 2001;(3):CD002124 [update in Cochrane Database Syst Rev 2016;3:CD002124] 